\title{
Evaluation of the Biomarkers HMGB1 and IL-6 as Predictors of Mortality in Cirrhotic Patients with Acute Kidney Injury
}

\author{
Célio Geraldo de Oliveira Gomes $\mathbb{D}^{1}{ }^{1}$ Marcus Vinicius Melo de Andrade, ${ }^{2}$ \\ Ludmila Resende Guedes, ${ }^{2}$ Henrique Carvalho Rocha, ${ }^{2}$ Roberto Gardone Guimarães, ${ }^{2}$ \\ Fernando Antônio Castro Carvalho, ${ }^{2}$ and Eduardo Garcia Vilela ${ }^{1,2}$ \\ ${ }^{1}$ Postgraduate Programme in Adult Health Applied Sciences, School of Medicine, Federal University of Minas Gerais, Brazil \\ ${ }^{2}$ Alfa Institute of Gastroenterology, Clinics Hospital, Federal University of Minas Gerais, Brazil \\ Correspondence should be addressed to Célio Geraldo de Oliveira Gomes; celiogog@hotmail.com
}

Received 16 June 2020; Revised 7 September 2020; Accepted 11 September 2020; Published 25 September 2020

Academic Editor: Raffaele Capasso

Copyright (c) 2020 Célio Geraldo de Oliveira Gomes et al. This is an open access article distributed under the Creative Commons Attribution License, which permits unrestricted use, distribution, and reproduction in any medium, provided the original work is properly cited.

\begin{abstract}
Background. Acute kidney injury (AKI) affects from $20 \%$ to $50 \%$ of cirrhotic patients, and the one-month mortality rate is $60 \%$. The main cause of AKI is bacterial infection, which worsens circulatory dysfunction through the release of HMGB1 and IL-6. Objectives. To evaluate HMGB1 and IL-6 as biomarkers of morbidity/mortality. Methods. Prospective, observational study of 25 hospitalised cirrhotic patients with AKI. Clinical and laboratory data were collected at the time of diagnosis of AKI, including serum HMGB1 and IL-6. Results. The mean age was 55 years; $70 \%$ were male. Infections accounted for 13 cases. The 30-day and three-month mortality rates were $17.4 \%$ and $30.4 \%$, respectively. HMGB1 levels were lower in survivors than in nonsurvivors at 30 days $(1174.2 \mathrm{pg} / \mathrm{mL}$ versus $3338.5 \mathrm{pg} / \mathrm{mL}, p=0.035)$, but not at three months $(1540 \mathrm{pg} / \mathrm{mL}$ versus $2352 \mathrm{pg} / \mathrm{mL}, p=0.243)$. Serum IL-6 levels were $43.3 \mathrm{pg} / \mathrm{mL}$ versus $153.3 \mathrm{pg} / \mathrm{mL}(p=0.061)$ at 30 days and $35.8 \mathrm{pg} / \mathrm{mL}$ versus $87.9 \mathrm{pg} / \mathrm{mL}(p=0.071)$ at three months, respectively. The area under the ROC curve for HMGB1 was 0.842 and 0.657 , and that for IL-6 was 0.803 and 0.743 for discriminating nonsurvivors at 30 days and three months, respectively. In multivariate analysis, no biomarker was independently associated with mortality. Conclusion. HMGB1 levels were associated with decreased survival in cirrhotics. Larger studies are needed to confirm our results.
\end{abstract}

\section{Introduction}

Acute kidney injury (AKI) is one of the most serious complications of cirrhosis, affecting from $20 \%$ to $50 \%$ of hospitalised patients $[1,2]$. Approximately $60 \%$ progress to death within 90 days [3]. Kidney failure is one of the main defining criteria for acute on chronic liver failure (ACLF), a syndrome that has long been known but has only recently been clearly defined. ACLF is characterised by acute decompensation of liver disease associated with organ failure and high shortand medium-term mortality $[4,5]$. Exacerbated systemic inflammation in response to a precipitating factor-bacterial infections and active alcoholism, for example-plays an important role in the development of ACLF [4]. The inflammatory mediators involved in this process include interleu- kin 6 (IL-6) and High-Mobility Group Box 1 (HMGB1) [4, $6,7]$.

HMGB1 is a proinflammatory nuclear protein actively secreted by cells of the innate immune system and released during apoptosis; it is also released by hepatocytes undergoing cell death $[8,9]$. HMGB1 is involved in the inflammatory response secondary to drug-induced kidney injury and ischaemia/reperfusion and is also secondary to hepatitis B and $C$ virus infections. It also actively participates in the pathophysiological mechanisms of nonalcoholic fatty liver disease, the progression of hepatic fibrosis, and the regulation of the development of hepatocellular carcinoma [9-11]. When interacting with Toll-like receptor 4 (TLR-4), a type of transmembrane pattern recognition receptor in one of its various signalling pathways, HMGB1 induces the activation 
of nuclear factor kappa B, producing immunostimulatory responses through transcriptional proinflammatory genes, including tumour necrosis factor, IL-1, and, finally, IL-6 [12]. Similarly, during sepsis, HMGB1 can accumulate in renal tissue and urine, stimulating renal tubular cells, through interaction with TLR-4 receptors, to secrete inflammatory cytokines, including IL-6 [13]. However, the role of these biomarkers as predictors of poor prognosis in cirrhotic patients is not yet known.

This study is aimed at evaluating the role of IL-6 and HMGB1 as predictors of mortality in cirrhotic patients with AKI admitted to the Clinics Hospital of the Federal University of Minas Gerais.

\section{Methods}

This is a prospective, observational study of cirrhotic patients older than 18 years of age hospitalised at the Clinics Hospital of the Federal University of Minas Gerais, diagnosed with AKI at admission or at any time during their hospitalisation. The exclusion criteria were dialysis prior to admission, previous liver or kidney transplant, and cancer (except hepatocellular carcinoma).

AKI was defined using the criteria proposed by the Acute Kidney Injury Network (AKIN) [14] and later revised by the International Club of Ascites (ICA) [15]. The presence of two serum creatinine values with a difference of at least $0.3 \mathrm{mg} / \mathrm{dL}$ within 48 hours, or a percentage increase $\geq 50 \%$ from the baseline which is known, or presumed, to have occurred within the prior 7 days, was used for the diagnosis of AKI. The baseline creatinine level was defined as the most recent and stable value prior to hospital admission within a maximum period of three months. Response to treatment was defined as complete when there was a return to creatinine value under $0.3 \mathrm{mg} / \mathrm{dL}$ of the baseline, incomplete when there was a regression in ICA-AKI stage with reduction of creatinine value of $0.3 \mathrm{mg} / \mathrm{dL}$ or more above the baseline value, or absent when there was no regression of AKI, that is, moving into milder ICA-AKI stage.

Patients were classified, from the aetiological point of view, into four groups: infection, hypovolemia, parenchymal renal disease, and hepatorenal syndrome. Once a possible case of AKI was identified, the patient underwent a careful review of their clinical history; full physical examination; laboratory tests including blood count, sodium, potassium, chloride, magnesium, glucose, liver enzymes, albumin, bilirubin, prothrombin time and INR, activated partial thromboplastin time, urinary sodium, urinary creatinine, urinary urea and urinalysis, blood culture, and urine culture; examination of ascitic fluid, if present, through a differential leukocyte count; measurement of lactate dehydrogenase, albumin, and total protein; culture (in blood culture bottles); and ultrasonography of the full abdomen, to establish the aetiology. The management of AKI followed the care protocol used by the Gastroenterology Department of the Clinics Hospital of the Federal University of Minas Gerais: [1] medications that could be associated with AKI are suspended, especially diuretics; [2] volume expansion according to the cause and degree of kidney failure (AKI patients with ICA-AKI 1 received $0.9 \%$ sodium chloride solution at a dose of 40 to $60 \mathrm{~mL} / \mathrm{kg}$ per day or $20 \%$ human albumin at a dose of $0.5 \mathrm{~g} / \mathrm{kg} /$ day for $48 \mathrm{~h}$ when they exhibited serum creatinine levels greater than $1.5 \mathrm{mg} / \mathrm{dL}$; those with ICA-AKI 2 and 3 received $20 \%$ human albumin at a dose of $1 \mathrm{~g} / \mathrm{kg} /$ day also for $48 \mathrm{~h}$ or packed red blood cells if the haemoglobin level was below $7 \mathrm{~g} / \mathrm{dL}$ or in cases of gastrointestinal bleeding); [3] in the presence of infection, antimicrobial treatment was administered; and [4] at diagnosis of hepatorenal syndrome type 1 , in addition to human albumin (20-30 g/day), patients received terlipressin or noradrenaline.

Peripheral blood was collected at the time of diagnosis of AKI to measure HMGB1 and IL-6 levels. The two biomarkers were measured by the ELISA method (HMGB1 ELISA ST51011, IBL International GmbH, Germany, and Human IL-6 Duoset ELISA, R\&D Systems, USA). Serum samples were stored in a freezer at $-80^{\circ} \mathrm{C}$.

During the hospitalisation period, demographic, clinical, and laboratory data were collected for the investigation of predictive factors of mortality. Demographic variables included age and sex; the clinical variables included ChildPugh, Model for End-stage Liver Disease (MELD) and MELD-Na scores, ICA-AKI stage, response to treatment with plasma expanders, and the presence of ascites and hepatic encephalopathy; the laboratory variables included creatinine, albumin, total bilirubin, INR, C-reactive protein, and sodium, in addition to the measurement of HMGB1 and IL-6 levels. All data, except the response to treatment of plasma expanders, were obtained at the time of AKI diagnosis.

The outcomes were 30-day and three-month mortality.

The study was approved by the Research Ethics Committee of the Federal University of Minas Gerais, and the patients who agreed to participate in the study signed an informed consent form.

2.1. Sample and Statistical Analysis. SPSS software for Windows version 17.0 (SPSS Inc., Chicago, IL) was used to perform the statistical analyses. The normality of the data was assessed using the Shapiro-Wilk test. Categorical variables are expressed as percentages. The associations between variables were analysed using Student's $t$-test, the MannWhitney test (according to the data distribution), or the chi-squared test (or Fisher's exact test when appropriate). Variables with a value of $p<0.2$ were included in the Cox regression analyses. The fit of the Cox regression model was assessed by the deviance test. The serum levels of HMGB1 and IL- 6 that best represented accuracy in predicting mortality were obtained using the ROC curve. A $p$ value $<0.05$ was adopted.

\section{Results}

Twenty-five patients were selected. Two were excluded from the survival analysis because they underwent liver transplantation during the follow-up period. Thus, 23 patients participated in the 30-day survival analysis. One patient was lost to follow-up and was not included in the three-month survival analysis (Figure 1). The mean age was $55.7( \pm 9.9)$ years, 


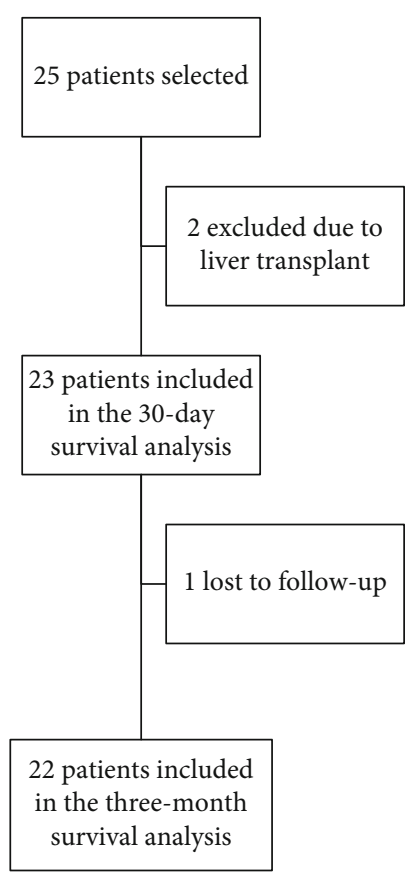

Figure 1: Sample, exclusions, losses, and final number of participants.

and $70 \%$ were male. The clinical and laboratory variables of the patients are listed in Table 1.

Of the 23 patients, 15 (65\%), seven (30\%), and one (4\%) were classified as ICA-AKI stages 1, 2, and 3, respectively. Among the causes of AKI, infections accounted for 13 (56\%) cases, hypovolemia accounted for nine (39.9\%) cases, and renal disease accounted for one (4\%) case. Spontaneous bacterial peritonitis was the most common cause of infection (six patients $-46 \%$ ); urinary tract infection, pneumonia, and bacteraemia were present in two cases each (15\%); sepsis of uncertain origin in one case $(7 \%)$. Hypovolemia was most commonly associated with the use of diuretics (six patients $-66 \%$ ), gastrointestinal bleeding (two patients $-22 \%$ ), and diarrhoea (one patient -11\%). There was no correlation between causes and AKI stages.

Clinical and laboratory variables were compared between survivors and nonsurvivors at 30 days and three months (Tables 2 and 3). Patients who were alive at the end of the first month had lower Child-Pugh, MELD and MELD-Na scores, INRs, and HMGB1 levels than did the nonsurvivors (10.3 versus $12.7, p=0.019 ; 20.2$ versus $31.5, p=0.05 ; 23.1$ versus $27.6, p=0.015 ; 1.5$ versus $3.1, p=0.009$; and $1174.2 \mathrm{pg} / \mathrm{mL}$ versus $3338.5 \mathrm{pg} / \mathrm{mL}, p=0.035$, respectively). Regarding serum IL-6 levels, the values were $43.3 \mathrm{pg} / \mathrm{mL}$ versus $153.3 \mathrm{pg} / \mathrm{mL}$, respectively $(p=0.061)$. Patients who responded to treatment were more common among survivors $(p=0.005)$. At three months, the MELD-Na score was significantly lower in the group of patients who survived (22.3 versus $29.4, p=0.044)$. In addition, the ICA-AKI stage also differed between the survivor and nonsurvivor groups $(p=0.045)$. At this time point, HMGB1 levels did not differ between survivors and nonsurvivors $(1540 \mathrm{pg} / \mathrm{mL}$ versus
TABLE 1: Clinical and laboratory variables of 23 cirrhotic patients with AKI.

\begin{tabular}{|c|c|}
\hline Characteristics $(n=23)$ & Mean $/$ median $/ n(\%)$ \\
\hline Age & 55.7 \\
\hline Gender (male/female) & $16(70 \%) / 7(30 \%)$ \\
\hline Mean blood pressure $(\mathrm{mmHg})$ & $64( \pm 5.8)$ \\
\hline Body weight (kg) & $72( \pm 7.7)$ \\
\hline Child-Pugh score & $10.8( \pm 1.9)$ \\
\hline Child-Pugh class (A/B/C) & $0 / 9(39 \%) / 14(71 \%)$ \\
\hline MELD & $22.17( \pm 7.7)$ \\
\hline MELD-Na & $24.6( \pm 7.6)$ \\
\hline \multicolumn{2}{|l|}{ Use of medications } \\
\hline Diuretics & $20(87 \%)$ \\
\hline Nephrotoxic agents & $1(4 \%)$ \\
\hline \multicolumn{2}{|l|}{ AKI stages } \\
\hline 1 & $15(65 \%)$ \\
\hline 2 & $7(30 \%)$ \\
\hline 3 & $1(4 \%)$ \\
\hline \multicolumn{2}{|l|}{ AKI causes } \\
\hline Infection & $13(56 \%)$ \\
\hline Hypovolemia & $9(39 \%)$ \\
\hline Hepatorenal syndrome & 0 \\
\hline Renal disease & $1(4 \%)$ \\
\hline HMGB1 (pg/mL) & $1697.2(0.1-6851.8)$ \\
\hline IL-6 (pg/mL) & $47.6(0.1-1107.3)$ \\
\hline Creatinine (mg/dL) & $1.99( \pm 0.7)$ \\
\hline Total bilirubin (mg/dL) & $4.6(0.4-15.3)$ \\
\hline Albumin $(\mathrm{g} / \mathrm{dL})$ & $2.5( \pm 0.4)$ \\
\hline INR & $1.6(1.0-5.0)$ \\
\hline Sodium $(\mathrm{mEq} / \mathrm{L})$ & $133.6( \pm 4.8)$ \\
\hline C-reactive protein $(\mathrm{mg} / \mathrm{L})$ & $34(9-287)$ \\
\hline
\end{tabular}

AKI: acute kidney injury.

$2352 \mathrm{pg} / \mathrm{mL}, \quad p=0.243)$. The serum IL-6 levels were $35.8 \mathrm{pg} / \mathrm{mL}$ versus $87.9 \mathrm{pg} / \mathrm{mL}(p=0.071)$. The mortality rate in this sample was $17.4 \%$ at 30 days and $30.4 \%$ at three months. The most common causes of death were hepatic failure (four cases), followed by acute intestinal bleeding (two cases) and respiratory failure and septic shock (one case each).

A Cox regression model was used to study the various predictors of mortality. Analysis of the 30-day outcome showed that the following variables had a $p$ value less than 0.2: Child-Pugh, MELD and MELD-Na scores, response to treatment with plasma expanders, total bilirubin, INR, sodium, IL-6, and HMGB1. For the 90-day outcome, the variables initially included in the Cox model were Child-Pugh, MELD and MELD-Na scores, response to treatment with plasma expanders, ICA-AKI stage, creatinine, and IL-6. After statistical analysis, the model did not identify any variables with a value of $p<0.05$ that were related to 30 -day mortality. In the analysis of prediction of three-month mortality, the only variable that remained associated with mortality was 
TABLE 2: Comparison of demographic, clinical, and laboratory variables between survivors and nonsurvivors at 30 days.

\begin{tabular}{|c|c|c|c|}
\hline & Survivors $(n=19)$ & Nonsurvivors $(n=4)$ & $p$ value \\
\hline \multicolumn{4}{|l|}{ Demographic } \\
\hline Age & $56.1( \pm 10.4)$ & $54( \pm 7.7)$ & 0.709 \\
\hline Males & $14(73.7 \%)$ & $2(50 \%)$ & \multirow{2}{*}{0.349} \\
\hline Females & $5(26.3 \%)$ & $2(50 \%)$ & \\
\hline \multicolumn{4}{|l|}{ Clinical } \\
\hline Child-Pugh & $10.3( \pm 1.7)$ & $12.7( \pm 1.5)$ & 0.019 \\
\hline MELD & $20.2( \pm 6.1)$ & $31.5( \pm 8.6)$ & 0.05 \\
\hline MELD-Na & $23.1( \pm 6.4)$ & $27.6( \pm 7.3)$ & 0.015 \\
\hline \multicolumn{4}{|l|}{ ICA-AKI stage } \\
\hline 1 & $13(68.4 \%)$ & $2(50 \%)$ & \multirow[t]{3}{*}{0.609} \\
\hline 2 & $5(26.3 \%)$ & $2(50 \%)$ & \\
\hline 3 & $1(5.3 \%)$ & 0 & \\
\hline \multicolumn{4}{|l|}{ AKI causes } \\
\hline Infection & $11(57.9 \%)$ & $2(50 \%)$ & \multirow[t]{4}{*}{0.822} \\
\hline Hypovolemia & $7(36.8 \%)$ & $2(50 \%)$ & \\
\hline Hepatorenal syndrome & 0 & 0 & \\
\hline Renal disease & $1(5.3 \%)$ & 0 & \\
\hline \multicolumn{4}{|c|}{ Response to treatment with plasma expanders } \\
\hline Complete & $12(63.2 \%)$ & $1(25 \%)$ & \multirow[t]{3}{*}{0.005} \\
\hline Partial & $7(36.8 \%)$ & $1(25 \%)$ & \\
\hline Absent & 0 & $2(50 \%)$ & \\
\hline \multicolumn{4}{|l|}{ Encephalopathy } \\
\hline Present & $6(31.6 \%)$ & $2(50 \%)$ & \multirow[t]{2}{*}{0.589} \\
\hline Absent & $13(68.4 \%)$ & $2(50 \%)$ & \\
\hline \multicolumn{4}{|l|}{ Ascites } \\
\hline Present & $17(89.5 \%)$ & $4(100 \%)$ & \multirow[t]{2}{*}{0.497} \\
\hline Absent & $2(17.1 \%)$ & 0 & \\
\hline \multicolumn{4}{|l|}{ Laboratory } \\
\hline HMGB1 (pg/mL) & $1174.2(0.1-6665)$ & $3338.5(2273-6851.8)$ & 0.035 \\
\hline IL-6 $(\mathrm{pg} / \mathrm{mL})$ & $43.3(0.1-135.6)$ & $153.3(21.1-1107)$ & 0.061 \\
\hline Creatinine $(\mathrm{mg} / \mathrm{dL})$ & $2.0( \pm 0.7)$ & $1.8( \pm 0.1)$ & 0.663 \\
\hline Total bilirubin (mg/dL) & $1.7(0.4-15.3)$ & $6(4.6-8.0)$ & 0.168 \\
\hline Albumin $(\mathrm{g} / \mathrm{dL})$ & $2.5( \pm 0.4)$ & $2.4( \pm 0.6)$ & 0.481 \\
\hline INR & $1.5(1.0-2.4)$ & $3.1(2.0-3.09)$ & 0.009 \\
\hline Sodium $(\mathrm{mEq} / \mathrm{L})$ & $133.2( \pm 5.4)$ & $134.8( \pm 4.3)$ & 0.127 \\
\hline C-reactive protein $(\mathrm{mEq} / \mathrm{L})$ & $34(9-287)$ & $28(18-46)$ & 0.626 \\
\hline
\end{tabular}

ICA-AKI: International Club of Ascites-Acute Kidney Injury.

response to treatment with plasma expanders (hazard ratio 5.7, CI 0.27-0.41, $p=0.012$ ).

Once the ROC curves were obtained, the cut-off values of the serum cytokine levels that most accurately predicted 30day mortality were $2.168 \mathrm{pg} / \mathrm{mL}$ and $73 \mathrm{pg} / \mathrm{mL}$ for HMGB1 and IL-6, respectively. These values were associated with sensitivity and specificity rates of $100 \%$ and $74 \%$, respectively, for serum HMGB1 levels, and $75 \%$ and $79 \%$, respectively, for serum IL-6 levels. The area under the curve was 0.842 for HMGB1 and 0.803 for IL-6 (Figure 2). In the analysis of three-month mortality, the cut-off value of HMGB1 was the same, and that of IL- 6 was $45 \mathrm{pg} / \mathrm{mL}$. The sensitivity and specificity were $71 \%$ and $73 \%$ for HMGB1 and $71 \%$ and $60 \%$ for IL-6, with areas under the curves of 0.657 and 0.743 , respectively (Figure 3 ).

\section{Discussion}

AKI is often related to circulatory dysfunction in cirrhosis, a condition for which the main risk trigger is splanchnic arterial vasodilation due to portal hypertension [16]. Neurohormones and other substances, such as vasopressin, angiotensin, aldosterone, epinephrine, and norepinephrine, are produced to compensate for the initial depletion of 
TABLE 3: Comparison of demographic, clinical, and laboratory variables between survivors and nonsurvivors at three months.

\begin{tabular}{|c|c|c|c|}
\hline & Survivors $(n=15)$ & Nonsurvivors $(n=7)$ & $p$ value \\
\hline \multicolumn{4}{|l|}{ Demographic } \\
\hline Age & $55.3( \pm 11.6)$ & $53.9( \pm 5.7)$ & 0.528 \\
\hline Males & 17 (65.4\%) & $16(72.7 \%)$ & \multirow{2}{*}{0.584} \\
\hline Females & $9(34.6 \%)$ & $6(33.3 \%)$ & \\
\hline \multicolumn{4}{|l|}{ Clinical } \\
\hline Child-Pugh & $10.3( \pm 1.7)$ & $11.6( \pm 2.1)$ & 0.134 \\
\hline MELD & $20.1( \pm 6.1)$ & $26.9( \pm 9.8)$ & 0.061 \\
\hline MELD-Na & $22.3( \pm 7.0)$ & $29.4( \pm 7.5)$ & 0.044 \\
\hline \multicolumn{4}{|l|}{ ICA-AKI stage } \\
\hline 1 & $12(80 \%)$ & $2(28.6 \%)$ & \multirow{3}{*}{0.045} \\
\hline 2 & $3(20 \%)$ & $4(57.1 \%)$ & \\
\hline 3 & $0(11.5 \%)$ & $1(14.3 \%)$ & \\
\hline \multicolumn{4}{|l|}{ AKI causes } \\
\hline Infection & $8(53.3 \%)$ & $4(57.1 \%)$ & \multirow[t]{4}{*}{0.783} \\
\hline Hypovolemia & $6(40 \%)$ & $3(42.9 \%)$ & \\
\hline Hepatorenal syndrome & 0 & 0 & \\
\hline Renal disease & $1(6.7 \%)$ & 0 & \\
\hline \multicolumn{4}{|c|}{ Response to treatment with plasma expanders } \\
\hline Complete & $10(66.7 \%)$ & $2(28.6 \%)$ & \multirow[t]{3}{*}{0.059} \\
\hline Partial & $5(33.3 \%)$ & $3(42.9 \%)$ & \\
\hline Absent & 0 & $2(28.6 \%)$ & \\
\hline \multicolumn{4}{|l|}{ Encephalopathy } \\
\hline Present & $4(26.7 \%)$ & $3(42.9 \%)$ & \multirow[t]{2}{*}{0.387} \\
\hline Absent & $11(73.3 \%)$ & $4(57.1 \%)$ & \\
\hline \multicolumn{4}{|l|}{ Ascites } \\
\hline Present & $13(86.7 \%)$ & $7(100 \%)$ & \multirow[t]{2}{*}{0.455} \\
\hline Absent & $2(13.3 \%)$ & $0(9.1 \%)$ & \\
\hline \multicolumn{4}{|l|}{ Laboratory } \\
\hline HMGB1 (pg/mL) & $1540(0.1-6665)$ & $2352(53.2-6851.8)$ & 0.243 \\
\hline IL-6 (pg/mL) & $35.8(0.1-113.5)$ & $87.9(4.4-1107.3)$ & 0.071 \\
\hline Creatinine $(\mathrm{mg} / \mathrm{dL})$ & $1.9( \pm 0.6)$ & $2.4( \pm 0.8)$ & 0.086 \\
\hline Total bilirubin (mg/dL) & $1.7(0.4-15.3)$ & $5.37(0.4-8.3)$ & 0.573 \\
\hline Albumin (g/dL) & $2.5( \pm 0.4)$ & $2.6( \pm 0.6)$ & 0.525 \\
\hline INR & $1.5(1-2.24)$ & $2.0(1.2-5.0)$ & 0.341 \\
\hline Sodium (mEq/L) & $133.3( \pm 4.4)$ & $132.8( \pm 5.5)$ & 0.829 \\
\hline C-reactive protein $(\mathrm{mEq} / \mathrm{L})$ & $30.8(5-278)$ & $31.6(5-287)$ & 0.860 \\
\hline
\end{tabular}

ICA-AKI: International Club of Ascites-Acute Kidney Injury.

effective intravascular volume. Therefore, an attempt is made to restore intravascular volume through ionic and fluid retention and release of molecules that would restore peripheral vascular resistance and cardiac output, which characterises the hyperdynamic circulation of cirrhotic patients [17].

Nevertheless, hyperdynamic circulation is not the only pathophysiological component of kidney dysfunction in cirrhosis. In fact, acute kidney failure, as well as other forms of organ dysfunction in cirrhosis, can occur in the absence of circulatory decompensation because it is secondary from the complicated interplay between the innate immune sys- tem and bacterial products-also known as pathogenassociated molecular patterns (PAMPs) — and antigens from dying cells, called damage-associated molecular patterns (DAMPs) [18-20]. Once connected to pattern recognition receptors, the PAMPs and DAMPs trigger various proinflammatory responses that, when excessive or chronic, can cause tissue damage $[6,18]$. Therefore, AKI in cirrhosis results not only from arterial vasodilation but also from uncontrolled systemic inflammation [16]. In fact, kidney failure is one of the main components of ACLF, which is a syndrome that, unlike "simple" acute decompensation of liver cirrhosis, is characterised by marked systemic inflammation, 


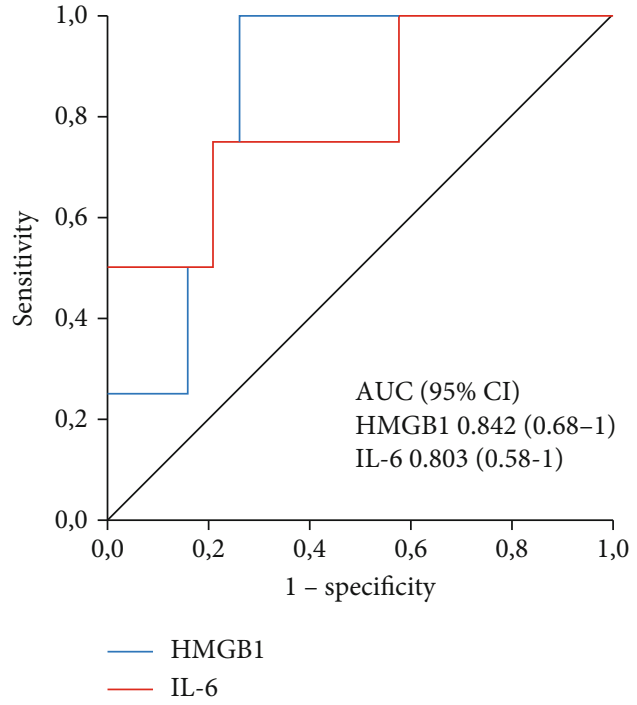

Figure 2: Receiver operator characteristic (ROC) curve and area under the curve (AUC) of HMGB1 and IL-6 in predicting onemonth mortality. AUC HMGB1 $=0.842(0.68-1)$; AUC IL-6 $=$ $0.803(0.58-1)$.

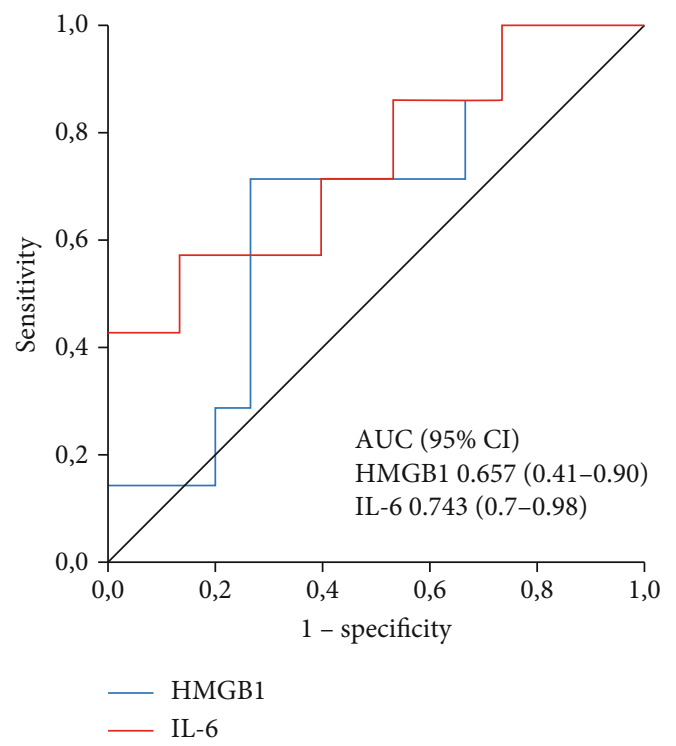

FIGURE 3: Receiver operator characteristic (ROC) curve and area under the curve (AUC) of HMGB1 and IL-6 in predicting threemonth mortality. AUC HMGB1 $=0.657$ (0.41-0.9); AUC IL-6 = $0.743(0.7-0.98)$.

organ failure, and high short-term mortality $[4,5]$. The mediators of acute or chronic inflammatory states that increase systemic vasodilation and are associated with AKI include HMGB1, a type of DAMP, and IL-6 [21].

In this study, we showed that HMGB1 levels could differentiate survivors from nonsurvivors at 30 days (median of $1174 \mathrm{pg} / \mathrm{mL}$ versus $3338 \mathrm{pg} / \mathrm{mL}, p=0.035$ ). Regarding IL-6, the $p$ value does not allow concluding that the median values of the two groups differed from each other $(43.3 \mathrm{pg} / \mathrm{mL}$ versus $153.3 \mathrm{ng} / \mathrm{mL}, p=0.061$ ). In the performance analysis, the two cytokines showed satisfactory discrimination of survivors from nonsurvivors at 30 days (areas under the ROC curve of 0.842 and 0.803 for HMGB1 and IL-6, respectively). At three months, unlike the first time point, the median serum levels of HMGB1 and IL-6 were not lower in the survivors $(1540 \mathrm{ng} / \mathrm{mL}$ versus $2352 \mathrm{ng} / \mathrm{mL}, p=0.243$ and $35.8 \mathrm{ng} / \mathrm{mL}$ versus $87.9 \mathrm{ng} / \mathrm{mL}, p=0.071$, respectively). However, the behaviour of IL- 6 at three months was quite similar to that at 30 days, as there was a tendency towards significance ( $p=0.061$ at 30 days and $p=0.071$ at three months). At three months, the area under the ROC curve of the two cytokines was also smaller. The areas under the curves were 0.657 and 0.743 , which were associated with sensitivity and specificity rates of $71 \%$ and $73 \%$ for HMGB1 and of $71 \%$ and $60 \%$ for IL-6. These results suggest that both cytokines may be good predictors of mortality, especially in the short term.

It is possible to state that the association between HMGB1 - and possibly IL-6-and survival is not an epiphenomenon because both cytokines are involved in the pathophysiology of AKI-associated organ failure [21-23]. In experimental models in which AKI was induced by bilateral nephrectomy or ischaemia, for example, it was possible to identify liver tissue damage, characterised by increases in leukocyte and cytokine influx, oxidative stress, and apoptosis [24-27]. However, the interaction between the liver and the kidneys is bidirectional; AKI in cirrhotic patients seems to be secondary not only to circulatory failure but also to inflammatory reactions mediated by TLR-4, among other mechanisms [28]. In fact, increased TLR-4 receptor levels were found in renal tubular cells of cirrhotic patients with AKI compared to those without AKI [29]. In animal models of induced cirrhosis, intestinal decontamination with norfloxacin, after the injection of bacterial lipopolysaccharides, was able to reduce the renal expression of these receptors, suggesting that they may mediate kidney injury in the context of infection or systemic inflammation [30]. In addition, blockage of HMGB1 by monoclonal antibodies protects against AKI and ACLF [31,32]. Although it is possible that the two cytokines may increase with liver damage, both HMGB1 and IL-6 showed no significant correlation with Child-Pugh and MELD scores in our cohort.

Since serum HMGB1 and IL-6 can accumulate in urine during AKI-associated inflammatory processes $[13,33]$, both could be useful in the differential diagnosis of the causes of AKI in cirrhosis patients-especially between parenchymal renal disease and functional AKI-similar to other urinary biomarkers [34]. However, since the absence of response to volume expansion is an important predictor of a poor prognosis in cirrhotic patients with AKI irrespective of its aetiology, the biomarkers' ability to differentiate between nonresponders and responders could reduce the costs and adverse effects of unnecessary treatments as well as optimise the allocation of patients on liver transplant waiting lists. In our study, HMGB1 and IL-6 showed good performance in predicting the absence of response to treatment (area under the ROC curve of 0.833 and 0.881 , respectively), with a sensitivity of $100 \%$ and specificities of $67.7 \%$ and $76.8 \% \%$, respectively, for cut-off values of $73.6 \mathrm{pg} / \mathrm{mL}$ of IL- 6 and $2168 \mathrm{pg} / \mathrm{mL}$ of HMGB1. In the multivariate analysis, the only 
variable that was associated with three-month mortality was the response to treatment with plasma expanders.

\section{Conclusions}

A literature search showed no other study that evaluated the role of HMGB1 and IL- 6 as predictors of mortality in cirrhotic patients with AKI. In our cohort, HMGB1 levels were associated with decreased survival in cirrhotics; both biomarkers showed good performance in predicting shortterm mortality. However, our study has limitations, such as the small size of our sample and its observational design. New studies with a larger number of patients are needed to evaluate the role of these cytokines in organ failure in cirrhosis and in the prognosis of cirrhotic patients with AKI.

\section{Data Availability}

Answer: Yes. Comment: The study data is available with the corresponding author upon request.

\section{Conflicts of Interest}

The authors declare that they have nothing to disclose.

\section{Acknowledgments}

The study was funded by the Fundação de Amparo à Pesquisa do Estado de Minas Gerais (FAPEMIG).

\section{References}

[1] G. Garcia-Tsao, C. R. Parikh, and A. Viola, "Acute kidney injury in cirrhosis," Hepatology, vol. 48, no. 6, pp. 20642077, 2008.

[2] P. Huelin, S. Piano, E. Sola et al., "Validation of a staging system for acute kidney injury in patients with cirrhosis and association with acute-on-chronic liver failure," Clinical Gastroenterology and Hepatology, vol. 15, no. 3, pp. 438445.e5, 2017, e5.

[3] G. Fede, G. D’Amico, V. Arvaniti et al., "Renal failure and cirrhosis: a systematic review of mortality and prognosis," Journal of Hepatology, vol. 56, no. 4, pp. 810-818, 2012.

[4] V. Arroyo, R. Moreau, R. Jalan, P. Gines, and EASL-CLIF Consortium CANONIC Study, "Acute-on-chronic liver failure: a new syndrome that will re-classify cirrhosis," Journal of Hepatology, vol. 62, no. 1, pp. S131-S143, 2015.

[5] R. Moreau, "Acute-on-chronic liver failure: a new syndrome in cirrhosis," Clinical and Molecular Hepatology, vol. 22, no. 1, pp. 1-6, 2016.

[6] R. Medzhitov, D. S. Schneider, and M. P. Soares, "Disease tolerance as a defense strategy," Science, vol. 335, no. 6071, pp. 936-941, 2012.

[7] R. Yang, X. Zou, J. Tenhunen, and T. I. Tonnessen, "HMGB1 and extracellular histones significantly contribute to systemic inflammation and multiple organ failure in acute liver failure," Mediators of Inflammation, vol. 2017, Article ID 5928078, 6 pages, 2017.

[8] M. T. Lotze and K. J. Tracey, "High-mobility group box 1 protein (HMGB1): nuclear weapon in the immune arsenal," Nature Reviews. Immunology, vol. 5, no. 4, pp. 331-342, 2005.
[9] R. Chen, W. Hou, Q. Zhang, R. Kang, X. G. Fan, and D. Tang, "Emerging role of high-mobility group box 1 (HMGB1) in liver diseases," Molecular Medicine, vol. 19, no. 1, pp. 357366, 2013.

[10] T. Yamamoto and Y. Tajima, "HMGB1 is a promising therapeutic target for acute liver failure," Expert Review of Gastroenterology \& Hepatology, vol. 11, no. 7, pp. 673-682, 2017.

[11] R. Zamora, D. Barclay, J. Yin et al., "HMGB1 is a central driver of dynamic pro-inflammatory networks in pediatric acute liver failure induced by acetaminophen," Scientific Reports, vol. 9, no. 1, p. 5971, 2019.

[12] J. S. Park, D. Svetkauskaite, Q. He et al., "Involvement of tolllike receptors 2 and 4 in cellular activation by high mobility group box 1 protein," The Journal of Biological Chemistry, vol. 279, no. 9, pp. 7370-7377, 2004.

[13] S. Zheng, Y. Pan, C. Wang, Y. Liu, M. Shi, and G. Ding, "HMGB1 turns renal tubular epithelial cells into inflammatory promoters by interacting with TLR4 during sepsis," Journal of Interferon \& Cytokine Research, vol. 36, no. 1, pp. 9-19, 2016.

[14] R. L. Mehta, J. A. Kellum, S. V. Shah et al., "Acute Kidney Injury Network: report of an initiative to improve outcomes in acute kidney injury," Critical Care, vol. 11, no. 2, p. R31, 2007.

[15] P. Angeli, P. Ginès, F. Wong et al., "Diagnosis and management of acute kidney injury in patients with cirrhosis: revised consensus recommendations of the International Club of Ascites," Journal of Hepatology, vol. 62, no. 4, pp. 968-974, 2015.

[16] V. Arroyo and J. Colmenero, "Ascites and hepatorenal syndrome in cirrhosis: pathophysiological basis of therapy and current management," Journal of Hepatology, vol. 38, Supplement 1, pp. 69-89, 2003.

[17] L. Ruiz-del-Arbol, A. Monescillo, C. Arocena et al., "Circulatory function and hepatorenal syndrome in cirrhosis," Hepatology, vol. 42, no. 2, pp. 439-447, 2005.

[18] M. Bernardi, R. Moreau, P. Angeli, B. Schnabl, and V. Arroyo, "Mechanisms of decompensation and organ failure in cirrhosis: from peripheral arterial vasodilation to systemic inflammation hypothesis," Journal of Hepatology, vol. 63, no. 5, pp. 1272-1284, 2015.

[19] T. Kawai and S. Akira, "The role of pattern-recognition receptors in innate immunity: update on Toll-like receptors," Nature Immunology, vol. 11, no. 5, pp. 373-384, 2010.

[20] H. Kumar, T. Kawai, and S. Akira, "Pathogen recognition by the innate immune system," International Reviews of Immunology, vol. 30, no. 1, pp. 16-34, 2011.

[21] K. Doi and H. Rabb, "Impact of acute kidney injury on distant organ function: recent findings and potential therapeutic targets," Kidney International, vol. 89, no. 3, pp. 555-564, 2016.

[22] N. Ahuja, A. Andres-Hernando, C. Altmann et al., "Circulating IL-6 mediates lung injury via CXCL1 production after acute kidney injury in mice," American Journal of Physiology. Renal Physiology, vol. 303, no. 6, pp. F864-F872, 2012.

[23] K. Doi, T. Ishizu, M. Tsukamoto-Sumida et al., "The highmobility group protein B1-Toll-like receptor 4 pathway contributes to the acute lung injury induced by bilateral nephrectomy," Kidney International, vol. 86, no. 2, pp. 316-326, 2014.

[24] F. Golab, M. Kadkhodaee, M. Zahmatkesh et al., "Ischemic and non-ischemic acute kidney injury cause hepatic damage," Kidney International, vol. 75, no. 8, pp. 783-792, 2009.

[25] S. W. Park, S. W. C. Chen, M. Kim et al., "Cytokines induce small intestine and liver injury after renal ischemia or 
nephrectomy," Laboratory Investigation, vol. 91, no. 1, pp. 6384, 2011.

[26] M. Serteser, T. Koken, A. Kahraman, K. Yilmaz, G. Akbulut, and O. N. Dilek, "Changes in hepatic TNF-alpha levels, antioxidant status, and oxidation products after renal ischemia/reperfusion injury in mice," The Journal of Surgical Research, vol. 107, no. 2, pp. 234-240, 2002.

[27] S. Miyazawa, H. Watanabe, C. Miyaji, O. Hotta, and T. Abo, "Leukocyte accumulation and changes in extra-renal organs during renal ischemia reperfusion in mice," The Journal of Laboratory and Clinical Medicine, vol. 139, no. 5, pp. 269278, 2002.

[28] D. Adebayo, V. Morabito, A. Davenport, and R. Jalan, "Renal dysfunction in cirrhosis is not just a vasomotor nephropathy," Kidney International, vol. 87, no. 3, pp. 509-515, 2015.

[29] N. Shah, F. E. Mohamed, M. Jover-Cobos et al., "Increased renal expression and urinary excretion of TLR4 in acute kidney injury associated with cirrhosis," Liver International, vol. 33, no. 3, pp. 398-409, 2013.

[30] N. Shah, D. Dhar, F. E. Z. Mohammed et al., "Prevention of acute kidney injury in a rodent model of cirrhosis following selective gut decontamination is associated with reduced renal TLR4 expression," Journal of Hepatology, vol. 56, no. 5, pp. 1047-1053, 2012.

[31] X. Li, L. K. Wang, L. W. Wang, X. Q. Han, F. Yang, and Z. J. Gong, "Blockade of high-mobility group box-1 ameliorates acute on chronic liver failure in rats," Inflammation Research, vol. 62, no. 7, pp. 703-709, 2013.

[32] H. Wu, J. Ma, P. Wang et al., "HMGB1 contributes to kidney ischemia reperfusion injury," Journal of the American Society of Nephrology, vol. 21, no. 11, pp. 1878-1890, 2010.

[33] P. Dennen, C. Altmann, J. Kaufman et al., "Urine interleukin-6 is an early biomarker of acute kidney injury in children undergoing cardiac surgery," Critical Care, vol. 14, no. 5, p. R181, 2010.

[34] J. M. Belcher, A. J. Sanyal, A. J. Peixoto et al., "Kidney biomarkers and differential diagnosis of patients with cirrhosis and acute kidney injury," Hepatology, vol. 60, no. 2, pp. 622$632,2014$. 